\title{
In memory of Dr. Nancy M. Petry
}

\author{
JEREMIAH WEINSTOCK ${ }^{1 *}$ and DAVID LEDGERWOOD ${ }^{2}$ \\ ${ }^{1}$ Department of Psychology, Saint Louis University, St. Louis, MO, USA \\ ${ }^{2}$ Department of Psychiatry \& Behavioral Neurosciences, Wayne State University, Detroit, MI, USA
}

(Received: August 20, 2018; accepted: August 21, 2018)

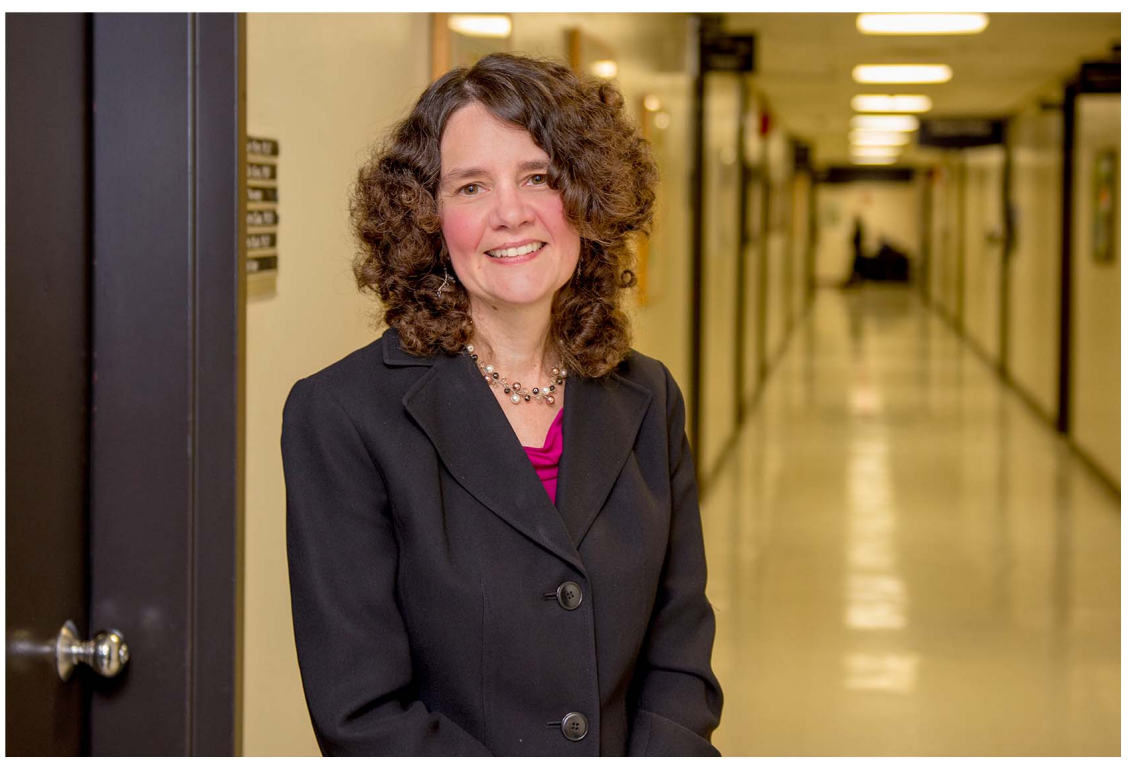

Dr. Nancy M. Petry passed away due to metastatic breast cancer on July 17, 2018, at the age of 49 . Her loss will be regretted by many, both personally and in our scientific field.

Nancy received her bachelor's degree from RandolphMacon College in Lynchburg, Virginia, and her $\mathrm{PhD}$ from Harvard University. She went on to complete a postdoctoral fellowship at University of Vermont, and became a faculty member at University of Connecticut School of Medicine in 1996. Nancy's highly innovative research quickly distinguished her as a trailblazer in the addictions field, and she became the youngest full professor with tenure in the history of University of Connecticut Medical School at the age of 34 . Throughout her career, she was continuously funded by the National Institutes of Health and other agencies, obtaining over $\$ 40$ million in grant funding.

Nancy's scientific contributions over her 22-year career reshaped the field of addiction both in its conceptualization and treatment. Her work was characterized by scientific rigor, clarity of thought, and a writing style that separated the wheat from the chaff. Her first major contribution was the development of prize-based contingency management, a behavioral substance use disorder intervention that reinforces completion of a target behavior (e.g., drug abstinence). Numerous clinical trials demonstrated that it is a robust and adaptable treatment approach. It is now disseminated and implemented around the world leading to improved treatment outcomes for individuals suffering from various substance use disorders.

Another major contribution was in the arena of gambling disorder. She applied her behaviorist theoretical orientation to understand the disorder and its treatment. She conducted several seminal clinical trials, demonstrating efficacy of cognitive behavioral therapy for the treatment of gambling disorder. She was also among the first to examine mechanisms of gambling disorder, exploring constructs such as discounting of delayed rewards. Moreover, as a member of the DSM-5 work group on substance-related disorders, she led the effort to reclassify gambling disorder as an addiction. It is the first behavioral addiction recognized within the psychiatric nosology. More recently, she turned her attention to Internet gaming disorder, another behavioral addiction that is likely to be included in the next revision of the DSM-5. Once again, Nancy was ahead of the curve. She convened an international panel to discuss its diagnostic formulation and to review the evidence for its validity. From there, she wasted little time in modifying and adapting a

\footnotetext{
* Corresponding author: Jeremiah Weinstock, PhD; Department of Psychology, Saint Louis University, 3700 Lindell Blvd., St. Louis, MO 63108, USA; Phone: +1 314977 2137; Fax: +1 314977 1014; E-mail: jeremiah.weinstock@health.slu.edu
}

This is an open-access article distributed under the terms of the Creative Commons Attribution-NonCommercial 4.0 International License, which permits unrestricted use, distribution, and reproduction in any medium for non-commercial purposes, provided the original author and source are credited, a link to the CC License is provided, and changes - if any - are indicated. 
behavioral treatment to test its efficacy in treating the disorder. In summary, Nancy was constantly pushing the field forward, expanding our understanding of what it means to be diagnosed with an addiction and enhancing best practices in its treatment. Below is a list of some of her most influential work selected from over 300 academic publications, including three books.

Her continuous pursuit of excellence was felt by those she worked with. No matter how many drafts a manuscript or grant application underwent, she always quickly provided an edit that critically improved the manuscript or clarified an argument. We can only imagine the red ink that would fly over this page! Nancy's mentorship of young investigators was incredibly effective. Throughout her career, she mentored numerous junior faculty, post-doctoral fellows, and graduate students. She took great care to teach young investigators the key elements of writing, analysis, research design and implementation, and importantly grantsmanship. Many of her past trainees have gone on to publish broadly and receive federal research funding, and for most of us, we owe a great deal of our success to Nancy's tutelage. Her scientific legacy is continued by those who are expanding her work to better understand and treat those who suffer from addictions. She will be greatly missed, and never forgotten.

Funding sources: There is no funding associated with this manuscript.

Authors' contribution: Drs. JW and DL worked collaboratively on this manuscript. Dr. JW completed the first draft and Dr. DL provided feedback and added additional content.

Conflict of interest: Drs. JW and DL declare no conflict of interest to disclose.

\section{SEMINAL ARTICLES BY DR. NANCY PETRY}

Alessi, S. M., \& Petry, N. M. (2003). Pathological gambling severity is associated with impulsivity in a delay discounting procedure. Behavioural Processes, 64, 345-354. doi:10.1016/ S0376-6357(03)00150-5

Kirby, K. N., Petry, N. M., \& Bickel, W. K. (1999). Heroin addicts have higher discount rates for delayed rewards than nondrug-using controls. Journal of Experimental Psychology. General, 128, 78-87. doi:10.1037/0096-3445.128.1.78

Petry, N. M. (2001). Pathological gamblers, with and without substance use disorders, discount delayed rewards at high rates. Journal of Abnormal Psychology, 110, 482-487. doi:10.1037/0021-843X.110.3.482

Petry, N. M., Ammerman, Y., Bohl, J., Doersch, A., Gay, H., Kadden, R., Molina, C., \& Steinberg, K. (2006). Cognitivebehavioral therapy for pathological gamblers. Journal of Consulting and Clinical Psychology, 74, 555-567. doi:10.1176/ appi.ajp.2009.08081235

Petry, N. M., Barry, D., Pietrzak, R. H., \& Wagner, J. A. (2008). Overweight and obesity are associated with psychiatric disorders: Results from the National Epidemiologic Survey on Alcohol and Related Conditions. Psychosomatic Medicine, 70(3), 288-297. doi:10.1097/PSY.0b013e3181 651651

Petry, N. M., Martin, B., Cooney, J. L., \& Kranzler, H. R. (2000). Give them prizes, and they will come: Contingency management treatment of alcohol dependence. Journal of Consulting and Clinical Psychology, 68, 250-257. doi:10.1037// 0022-006X.68.2.250

Petry, N. M., Rehbein, F., Gentile, D. A., Lemmens, J. S., Rumpf, H. J., Mößle, T., Bischof, G., Tao, R., Fung, D. S., Borges, G., Auriacombe, M., González Ibáñez, A., Tam, P., \& O’Brien, C. P. (2014). An international consensus for assessing Internet gaming disorder using the new DSM-5 approach. Addiction, 109, 1399-1406. doi:10.1111/add.12457

Petry, N. M., Stinson, F. S., \& Grant, B. F. (2005). Comorbidity of DSM-IV pathological gambling and other psychiatric disorders: Results from the National Epidemiologic Survey on Alcohol and Related Conditions. Journal of Clinical Psychiatry, 66, 564-574. doi:10.4088/JCP.v66n0504

Petry, N. M., Weinstock, J., Ledgerwood, D. M., \& Morasco, B. (2008). A randomized trial of brief interventions for problem and pathological gamblers. Journal of Consulting and Clinical Psychology, 76, 318-328. doi:10.1037/0022006X.76.2.318 